\title{
PERCEPÇÕES DE ESTAGIÁRIOS DA EDUCAÇÃO FÍSICA SOBRE O ESTÁGIO SUPERVISIONADO NA EDUCAÇÃO INFANTIL
}

\author{
Jessica Almeida Isbarrolal \\ Jaqueline Copetti2
}

\section{RESUMO}

A Educação Física (EF) é obrigatória em todas as fases da Educação Básica, entretanto na Educação Infantil (EI) não há obrigatoriedade de aulas ministradas por profissionais de EF. Mesmo com essa problemática o currículo das Licenciaturas proporciona o reconhecimento da realidade docente a partir dos estágios supervisionados curriculares (ECS). Esse estudo buscou analisar as percepções de estagiários de EF referentes às experiências positivas e negativas encontradas em seus ECS na El, através de uma pesquisa documental e qualitativa. Os documentos utilizados neste estudo foram os relatórios finais do ECS na El de discentes, de ambos os sexos, aprovados no primeiro semestre dos anos de 2015 (8 relatórios), 2016 (9 relatórios) e 2017 (11 relatórios), os quais realizaram este como o primeiro estágio. A técnica de análise utilizada para examinar os resultados foi a Análise de Conteúdo de Bardin. Os resultados foram analisados a partir de quatro categorias que identificaram 25 palavras-chave. Conforme a frequência apurada de cada palavra-chave as que tiveram maior frequência foram: Agitados (73); Participação dos alunos(156); e Controle da turma (37). A relação dessas palavras-chave permite concluir que as experiências classificam-se em negativas e positivas, contribuindo na formação acadêmica e pessoal de cada estagiário. Assim, concluiu-se que a interação entre Universidade e Escola abrange benefícios além da contribuição na formação acadêmica dos discentes, englobam novos conhecimentos e o desenvolvimento de todos os participantes das experiências dos estágios.

Palavras-chave: Educação Física. Educação Infantil. Estágio Supervisionado.

\section{PERCEPTIONS OF PHYSICAL EDUCATION TRAINEES ABOUT SUPERVISED PRACTICUM IN CHILDREN EDUCATION}

\begin{abstract}
Physical Education (PE) is compulsory in all phases of primary and secondary education; however, in Child Education (CE), PE lessons do not need to be taught by $\mathrm{PE}$ professionals. Even with this problem, the curriculum of licensure programs

1 Licenciada em Educação Física pela Universidade Federal do Pampa, Campus Uruguaiana. E-mail: je.isbarrola@hotmail.com

2 Doutorado em Educação em Ciências: Química da Vida e Saúde. Professora da Universidade Federal do Pampa, Campus Uruguaiana. E-mail:
\end{abstract} jaquelinecopetti@unipampa.edu.br 
provides the recognition of the reality of teaching from the supervised curricular practicum (SCP). This study aimed to analyze the perceptions of PE trainees regarding the positive and negative experiences that they found in their SCP in CE through documentary and qualitative research. The documents used in this study were the final SCP reports in the CE of male and female students who succeeded in the exams in the first half of 2015 (8 reports), 2016 (9 reports) and 2017 (11 reports). This was the first school practicum that the trainees participated. Bardin's Content Analysis was used in the analysis of the reports. In the analysis of the reports, 25 keywords were used from which four categories emerged. According to the frequency of each keyword, the most frequent ones were: Agitated (73); Student participation (156); and Class Control (37). The relationship of these keywords allows the conclusion that the experiences are classified as negative and positive, contributing to the academic and personal development of each trainee. Thus, it was concluded that the interaction between university and school encompasses benefits beyond the contribution to the academic development of the students, new knowledge and the development of all participants of the experiences of the school practicum.

Keywords: Physical Education, Early Childhood Education, Supervised practicum.

\section{PERCEPCIONES DE LOS PASANTES DE EDUCACIÓN FÍSICA SOBRE EL ESPACIO DE LA PRÁCTICA SUPERVISADA EN LA EDUCACIÓN INFANTIL}

\section{RESUMEN}

La Educación Física (EF) es obligatoria en todas las fases de la Educación Básica, sin embargo en la Educación Infantil (EI) no hay obligatoriedad de clases impartidas por profesionales de EF. Incluso con esta problemática el currículo de las Licenciaturas proporciona el reconocimiento de la realidad docente a partir del espacio curricular de práctica supervisada (ECS). Este estudio busca analizar las percepciones referentes a las experiencias positivas y negativas que los aprendices de EF encontraron en sus ECS en la El a través de una investigación documental y cualitativa. Los documentos utilizados en este estudio fueron los informes finales del ECS en la El de los estudiantes de ambos sexos aprobados en el primer semestre de los años 2015 (8 informes), 2016 (9 informes) y 2017 (11 informes), los cuales realizaron este como la primera etapa. El método utilizado para organizar los resultados fue el análisis de contenido de Bardin. Los resultados fueron analizados a partir de cuatro categorías que identificaron 25 palabras clave. Conforme la frecuencia calculada de cada palabra clave las que tuvieron mayor frecuencia fueron: Agitados (73); Participación de los alumnos (156); y Control de la clase (37). La relación de estas palabras clave permite concluir que las experiencias se clasifican en negativas y positivas, contribuyendo en la formación académica y personal de cada pasante. Así, se concluyó que la interacción entre Universidad y Escuela abarca beneficios más allá de la contribución en la formación académica de los discentes, engloban nuevos conocimientos y el desarrollo de todos los participantes de las experiencias de las pasantías.

Palabras clave: Educación Física, Educación Infantil, Ełapa Supervisada. 


\section{INTRODUÇÃO}

As escolas de Educação Infantil (El) foram criadas a partir da necessidade que as mães estavam enfrentando com a implementação das mulheres no mercado de trabalho. Com o passar dos anos, as creches tiveram uma reorganização em seus currículos, passaram dos cuidados (higiênicos, alimentícios e físicos) para o ensino, um currículo comum que visa trabalhar aspectos físicos, sociais e psicológicos das crianças de zero a cinco anos e onze meses (RODRIGUES e MOLINA, 2013).

Segundo a Lei 9394 Art. 29, a primeira etapa da Educação Básica deveria complementar a bagagem cultural que cada criança carrega consigo, oriunda do aprendizado construído junto aos responsáveis, focando no desenvolvimento integral do indivíduo, entretanto, não é o que se encontra nas instituições escolares. Por mais que se tenha um Projeto Político Pedagógico e uma organização curricular é transferida para os professores a missão do cuidado e da educação que deveria ser de responsabilidade dos pais, como estipular limites e regras sociais às crianças. Assim, a escola perdeu o foco da aprendizagem e passou a ser instrumento de correção dos aspectos negativos da sociedade, como se tivesse condições socioeconômicas e estruturais para manter-se em funcionamento e amenizar as sequelas que a má administração dos órgãos responsáveis pelo país está causando em cada indivíduo da sociedade (NÓVOA, 2007).

A reorganização do currículo da El não contemplou integralmente a área do movimento corporal, focando apenas na psicomotricidade. Nesse sentido, Sayão (1999) enfatiza a importância da não fragmentação do currículo da El, visto que a criança é o sujeito detentor de cultura. Para a autora, indivíduos que contemplam essa faixa etária criam e recriam a linguagem do movimento através do brincar, do imitar, dos jogos e, a partir das suas interações sociais tornam-se sujeitos que denotam cultura, não sendo possível fragmentar o conhecimento. O que fica explícito no estudo da autora: 
O currículo de Educação Infantil precisa contemplar as formas de manifestação características da criança de zero a seis anos de idade, privilegiando as diferentes linguagens que se externam através da oralidade, dramaticidade, leitura, escrita, musicalidade, corporeidade, gestualidade [...] (SAYÃO, 1999, p.234).

Assim, a inserção do profissional de Educação Física (EF) na pré-escola contribuiria para a formação integral da criança, a partir de um currículo que contemplasse a interação entre os profissionais envolvidos. Conforme a Lei de Diretrizes e Bases da Educação Nacional (Art. 26/1996) a EF é obrigatória em todos os períodos escolares, porém, a legislação não abrange qual profissional é responsável pela EF na El, sendo assim, as aulas não são obrigatoriamente ministradas por um profissional licenciado em EF, ficando na maioria das vezes sob responsabilidade do professor de sala.

Sabe-se que nos currículos da Pedagogia e Magistério existe um componente curricular voltado para as possíveis práticas a serem desenvolvidas nas aulas de EF, porém, são mais voltados para as manifestações recreacionistas (MENTZ, 2011). Esse planejamento de brincadeiras sem uma organização didática e professores sem habilitação em EF faz com que a escola pública se diferencie da privada, pois a maioria das escolas de El privadas possuem professores de EF, determinando uma pressão para implementação dos educadores habilitados no currículo, entretanto, as disputas político-pedagógicas e o aumento no salário da(o)s professora(o)s regentes em alguns estados brasileiros, como por exemplo o Rio Grande do Sul, faz com que a EF no Ensino Infantil siga sem uma organização curricular (SAYÃO, 1999).

Para melhor entender a realidade da EF no Ensino Infantil as Universidades proporcionam vivências práticas aos discentes durante a graduação em Licenciatura em EF. Essas vivências são desenvolvidas durante os Estágios Curriculares Supervisionados (ECS) que geralmente são realizados nos semestres finais do curso. Alguns autores apontam que (KRUG et al., 2015; PIMENTA e LIMA, 2005/2006; PIMENTA, 1995; KULCSAR, 1991), os ECS apresentam grande importância no aprendizado dos acadêmicos, pois proporcionam o reconhecimento das áreas de atuação do profissional e a 
oportunidade de avaliar as possiveis abordagens metodológicas que serão desenvolvidas com a contribuição e correção do docente supervisor e professores escolares dos ECS.

Para Krug e Krug (2013) é durante o ECS que os acadêmicos exercitam a transição da condição de estudantes para a condição de professor. Corroborando com os resultados encontrados por Silva (2003), onde afirma que o ECS além de integrar a teoria com a prática desenvolve um pensar crítico e criativo aos discentes, sendo possível analisar a partir desses aspectos as dificuldades que os acadêmicos encontram.

O estágio supervisionado é a oportunidade que o discente possui em sua formação inicial de ter contato com a realidade escolar e na maioria dos casos, esse primeiro contato acarreta numa percepção chocante, pois na maioria das vezes a experiência prática não corresponde com a teoria (PIMENTA e LIMA, 2012). A experiência adquirida durante os estágios poderá fazer com que o acadêmico desista do curso escolhido ou fará com que tenha certeza da escolha de sua profissão; também é possível avaliar e compreender as dificuldades encontradas, estudando a melhor forma de corrigi-las e adaptá-las.

Sabe-se da importância que a cultura do movimento proporciona às crianças do Ensino Infantil, porém, a não presença do professor de EF nessa fase enaltece a escassez de estudos, debates e pesquisas que contribuiriam para a obrigatoriedade de aulas ministradas por professores com formação em EF (BASEl, 2008). Dessa forma, a escolha pelos relatórios dos ECS na El se dá pelo fato de que há poucas pesquisas nessa temática (análise das percepções dos estagiários) e pela importância que a EF tem nessa faixa etária. E também, pela variedade de informações sobre a organização escolar, estruturas, relações interpessoais e aspectos comportamentais registrados nos relatos dos estagiários. O tratamento dos dados produzidos com a análise de conteúdo de Bardin permitiu explorar e considerar a importância e abundância de elementos elaborados durante os anos de graduação pelos acadêmicos e que na maioria das Universidades não são utilizados como fontes de pesquisas. 
Assim, esse estudo buscou analisar as percepções de estagiários de EF referentes às experiências positivas e negativas encontradas em seus ECS na El.

\section{Procedimentos metodológicos}

A pesquisa caracteriza-se como um estudo documental com análise de dados utilizando a interpretação qualitativa. A pesquisa qualitativa busca analisar os dados a partir da abordagem hermenêutica (compreensão e interpretações de textos), dando ênfase às práticas estudadas (GONSALVES, 2001). A obtenção dos dados se deu pela pesquisa documental, que segundo Godoy (1995), é uma rica fonte de dados que possibilita diversas análises e estudos, a autora ressalta ainda, que um dos aspectos importante em relação à pesquisa documental é de que os documentos não se modificam com o passar do tempo, aquilo que foi escrito seguirá por décadas.

Os documentos utilizados neste estudo têm caráter primário, pois foram elaborados pelos indivíduos atuantes na vivência relatada. Como são documentos pessoais, foi necessário solicitar a autorização dos autores desses relatórios para se ter acesso a essas produções textuais. O relatório final é uma das atividades da metodologia avaliativa do componente de ECS do Curso de Licenciatura em Educação Física da Universidade Federal do Pampa, esse relatório deve seguir um modelo estipulado pela docente responsável pelo componente e, normalmente, abrange: Introdução, Projeto, Desenvolvimento e relato das aulas práticas, reflexões e considerações finais com as percepções dos discentes sobre os estágios. $O$ ECS na El é o primeiro estágio obrigatório do Curso de Educação Física desta Universidade. Assim, os relatórios avaliados neste estudo são de discentes, de ambos os sexos, aprovados no ECS na El no primeiro semestre dos anos de 2015, 2016 e 2017, os quais realizaram este como o primeiro ECS.

A técnica de análise utilizada para organizar os resultados foi a Análise de Conteúdo de Bardin, o qual utiliza como orientação de análise a divisão em três etapas: 1) Pré-análise: primeiro contato com os documentos, 
definição e formatação do que será realizado; 2) Exploração do material: leitura dos documentos, cumprimento das decisões e a categorização; e, 3) Tratamento dos resultados: lapidar os dados, interpretação além dos conteúdos encontrados (BARDIN, 2011).

Conforme os objetivos específicos desse estudo foi elaborada uma matriz para a análise dos relatórios finais de estágio na El, composta por quatro categorias que nortearam a descrição dos resultados encontrados, sendo elas: 1) Comportamento dos educandos durante as intervenções pedagógicas; 2) Percepções positivas referente à intervenção na El; 3) A relação e conflitos com os professores titulares e os supervisores do ECS; e, 4) As dificuldades encontradas pelos estagiários nas intervenções dos ECS.

Os dados deste artigo fazem parte de um projeto de pesquisa maior registrado no Sistema de Informações de Projetos de Pesquisa, Ensino e Extensão da Universidade Federal do Pampa, com aprovação no Comitê de Ética em Pesquisa local sob o parecer de número: 1.840.192.

\section{RESULTADOS E DISCUSSÕES}

A partir do interesse de compreender as percepções dos estagiários que concluíram o ECS na El, analisou-se um total de 28 relatórios produzidos nos anos de 2015 (8 relatórios), 2016 (9 relatórios) e 2017 (11 relatórios).

A pesquisa documental sofreu algumas perdas que foram resultantes do não retorno dos termos de consentimento e da não disponibilidade de alguns relatórios. Cabe salientar que outros relatórios também foram descartados devido ao ECS na El não ter sido o primeiro estágio na formação acadêmica de alguns discentes. Em função do currículo do curso de EF desta Universidade não possuir pré-requisitos para a realização dos componentes curriculares alguns acadêmicos optam por inverter a ordem dos estágios, começando pelo Ensino Médio ou Ensino Fundamental.

\section{Comportamento dos educandos durante as intervenções pedagógicas}

Ao ingressar nas aulas práticas dos componentes de estágios, os acadêmicos normalmente realizam alguns dias de observações. Essas 
observações servem para o reconhecimento da rotina daqueles indivíduos que serão sujeitos das práticas em um determinado período de tempo. Esse pequeno processo não garante a descoberta de todos os aspectos que poderão surgir durante as intervenções, e na El torna-se difícil prever com antecedência as prováveis consequências de determinados planejamentos. Entre esses aspectos, as atitudes das crianças é um dos principais fatores que interferem de forma significativa no decorrer das aulas e, em muitas situações, faz com que os estagiários repensem seus planos de aulas.

A partir dos recortes sobre o comportamento dos estudantes nos relatórios analisados, surgiram sete unidades de palavras-chave durante os três anos estudados, estas serão apresentadas no Quadro 1, conforme a frequência de relatos. As palavras-chave que tiveram frequência inferior a 10 serão descritas no corpo do texto.

QUADRO 1 - Palavras-chave e recortes relacionados ao comportamento

\begin{tabular}{|c|c|c|c|}
\hline $\begin{array}{l}\text { Palavras- } \\
\text { chave }\end{array}$ & Recortes 2015 & Recortes 2016 & Recortes 2017 \\
\hline $\begin{array}{c}\text { Agitados } \\
\text { Frequência: } \\
2015-22 \\
2016-25 \\
2017-26\end{array}$ & $\begin{array}{l}\text { [...] pegamos uma } \\
\text { turminha bastante } \\
\text { agitada, com alguns } \\
\text { problemas individuais } \\
\text { [...] (Relatório 6) } \\
\\
\text { [...] A turma é grande e } \\
\text { agitada, são falantes e } \\
\text { alegres [...] (Relatório 3) }\end{array}$ & $\begin{array}{l}\text { [...] mais agitados fazendo } \\
\text { com que perdessem a } \\
\text { atenção na aula [...] } \\
\text { (Relatório 1) } \\
\text { [...] decidimos fazer a } \\
\text { próxima em sala de aula, } \\
\text { para descobrir se o agito } \\
\text { deles era só naquele dia } \\
\text { [...] (Relatório 3) }\end{array}$ & $\begin{array}{l}\text { [...] Eles estavam bem } \\
\text { agitados, foi difícil de } \\
\text { manter o controle [...] } \\
\text { (Relatório 7) } \\
\\
\text { [...] ficaram muito } \\
\text { agitados e acabamos } \\
\text { perdendo na } \\
\text { organização [...] } \\
\text { (Relatório 4) }\end{array}$ \\
\hline $\begin{array}{l}\text { Dispersos } \\
\text { Frequência: } \\
2015-15 \\
2016-16 \\
2017 \text { - } 29\end{array}$ & $\begin{array}{c}\text { [...]conduziu muito bem } \\
\text { as ações e foi uma } \\
\text { ótima aula, alguns } \\
\text { dispersos [...] (Relatório } \\
\text { 5) } \\
\\
\text { [...] bem participativos, } \\
\text { porém como de } \\
\text { costume agitados, se } \\
\text { dispersam rapidamente } \\
\text { [...] (Relatório 6) }\end{array}$ & $\begin{array}{c}\text { [...] os alunos de início } \\
\text { realizaram os desenhos } \\
\text { sem dificuldades, mas em } \\
\text { seguida dispersaram e } \\
\text { começaram a brigar entre } \\
\text { si [...] (Relatório 9) } \\
\\
\text { [...] os alunos estavam } \\
\text { muito dispersos, não } \\
\text { comportando-se } \\
\text { adequadamente [...] } \\
\text { (Relatório 1) }\end{array}$ & $\begin{array}{c}\text { [...] notamos que eles } \\
\text { são muito dispersos na } \\
\text { hora da explicação de } \\
\text { como executar, } \\
\text { fazendo com que } \\
\text { depois eles tenham } \\
\text { dúvidas [...] (Relatório } \\
\text { 8) } \\
\\
\text { [...] chamar um por um } \\
\text { foi difícil pois gerou } \\
\text { muita dispersão [...] } \\
\text { (Relatório 9) }\end{array}$ \\
\hline $\begin{array}{l}\text { Receosos } \\
\text { Frequência: } \\
2015 \text { - } 10\end{array}$ & $\begin{array}{l}\text { [...] A aula transcorreu } \\
\text { tranquilamente, mesmo } \\
\text { que alguns ficassem } \\
\text { receosos em participar }\end{array}$ & $\begin{array}{l}{[. . .] \text { muitos alunos }} \\
\text { demonstraram medo ao } \\
\text { realizar o movimento [...] } \\
\text { (Relatório 8) }\end{array}$ & $\begin{array}{c}\text { [...] um certo receio da } \\
\text { turma em realizar as } \\
\text { atividades, [...] } \\
\text { (Relatório 8) }\end{array}$ \\
\hline
\end{tabular}




\begin{tabular}{|c|c|c|c|}
\hline $\begin{array}{l}2016-07 \\
2017-02\end{array}$ & [...] (Relatório 7) & & \\
\hline $\begin{array}{c}\text { Tímidos } \\
\text { Frequência: } \\
2015 \text { - } 04 \\
2016-04 \\
2017-04\end{array}$ & $\begin{array}{l}\text { [...] alguns alunos se } \\
\text { mostravam tímidos, } \\
\text { mas mesmo assim } \\
\text { participavam [...] } \\
\text { (Relatório 7) } \\
\\
\text { [...] a timidez de alguns } \\
\text { educandos era comum } \\
\text { principalmente no } \\
\text { decorrer das primeiras } \\
\text { atividades [...] } \\
\text { (Relatório 5) }\end{array}$ & $\begin{array}{l}\text { [...] ficava tímidos e não } \\
\text { tocavam as mãos [...] } \\
\text { (Relatório } 8) \\
\text { [...] todos gostaram muito } \\
\text { mas ficaram um tímidos } \\
\text { na realização [...] } \\
\text { (Relatório 9) }\end{array}$ & $\begin{array}{c}\text { Muito tímidos, } \\
\text { começam a participar } \\
\text { das atividades, [...] } \\
\text { (Relatório 6) }\end{array}$ \\
\hline
\end{tabular}

Fonte: As autoras, 2017.

A agitação das crianças foi o aspecto com o maior número de frequência nos três anos. A partir dos relatos dos acadêmicos, percebeu-se que a agitação estava associada aos espaços físicos, a problemas de convivência e, também, um comportamento natural dessa faixa etária. Mello et al. (2014) identifica nos relatos do seu estudo a mudança de humor das crianças, semelhante ao que foi relatado pelos estagiários de EF nesta pesquisa. O autor confirma seu achado com o que Vygotsky (1987 apud MELLO, 2014) caracteriza como processo imitativo, onde as crianças demonstram o que sentem e o que querem através das atitudes e das mudanças delas.

Esses aspectos influenciaram o desenvolvimento das aulas de forma com que os estagiários não prosseguissem com as atividades planejadas ou, que criassem estratégias que resolvessem a questão da agitação, não interferindo no andamento das práticas. Para Gonçalves (2007) uma dessas estratégias é criar normas em conjunto com as crianças, como atitudes a serem seguidas e com consequências caso não sejam cumpridas. Além de colaborar com o desenvolvimento das aulas, esse método acaba contribuindo para o aprendizado de socialização dos envolvidos.

A dispersão foi o segundo comportamento mais apontado durante as análises dos relatórios, e no ano de 2017 a frequência (29) deste foi maior que todas as outras palavras-chave dessa categoria. Conforme as afirmações dos estagiários foi possível identificar que a dispersão pode estar 
relacionada aos estímulos e objetos que chamam a atenção dos educandos, principalmente quando as aulas são desenvolvidas nas pracinhas ou na sala de aula. Talvez esse comportamento esteja relacionado ao fato de que nessa faixa etária os estudantes não conseguem ficar passivos por um período de tempo longo, principalmente quando as aulas não são agradáveis.

Miranda e Afonso (2006) salientam a necessidade de planejar atividades coerentes às individualidades de cada estudante e a faixa etária, levando em consideração que cada criança traz consigo uma cultura diferente. Esse processo de reconhecimento faz com que o estudante se sinta pertencente aquela atividade e local que está inserido, enriquecendo a participação e a aprendizagem. Para Oliveira (2013) o processo de ensino deve ter caráter atrativo, para que haja o interesse e a satisfação ao desenvolver as atividades.

A partir das afirmações, analisou-se que $\circ 3^{\circ}$ e $4^{\circ}$ significado dessa categoria, Receio e Timidez, são aspectos que se remetem praticamente a mesma discussão. Ambos os comportamentos são ligados a chegada de pessoas diferentes da rotina escolar, da aprendizagem de novos movimentos e a vergonha de realizar determinadas atividades. Neste sentido, é possível cogitar que esses comportamentos que surgiram durante as intervenções dos estagiários dar-se-á do convívio rotineiro com uma professora Unidocente e auxiliares durante o ano.

$\mathrm{Na} \mathrm{El}$ as crianças elegem os professores como ponto de referência e segurança na ausência dos responsáveis, e pelo fato dos estágios terem período limitado para serem realizados, acaba caracterizando os acadêmicos como estranhos que chegam com propostas e rotinas diferentes daquilo que eles estavam acostumados e em pouco tempo deixam de participar da rotina escolar dos envolvidos.

Outros aspectos referentes ao comportamento foram elencados como: Felizes, Carinhosos e Calmos. Ambos tiveram o somatório das frequências, durante os três anos, inferior ou igual a dez. Ao analisarmos os relatos, identificamos que esses aspectos variam conforme as crianças, as 
escolas, a professora titular e, principalmente, como cada estagiário vai conduzir as aulas e a capacidade afetiva de se relacionar com as crianças.

Conforme o aumento da faixa etária das crianças houve, também, o aumento das frequências das palavras-chave Agitados e Dispersos, neste aspecto podemos associar a falta de limites por parte dos responsáveis e também, o avanço tecnológico que deixa as crianças mais sedentárias, extrapolando suas energias durante o período em que estão na escola.

Essa mudança de comportamento pode estar associada a fatores internos e externos a escola. Segundo Candreva et al (2009) a separação da família faz com que a criança mude suas atitudes, por mais que esta seja bem cuidada no ambiente escolar, ela divide a atenção da docente com os outros colegas, tornando a necessidade de criar atributos que chamem a atenção para si. Farias et al (2007) relata a importância do educador em conhecer o contexto familiar e escolar em que seus educandos estão inseridos, esse reconhecimento agrega no planejamento e, posteriormente, no entendimento das atitudes das crianças durante as práticas.

\section{Percepções positivas referentes à intervenção na Educação Infantil pedagógicas}

Essa categoria buscou analisar as percepções positivas das intervenções, interpretando os fatos que auxiliaram para um bom andamento das aulas ou para experiência profissional. Neste sentido, surgiram sete subcategorias que são apresentadas no Quadro 2 conforme o número de apuramentos das palavras-chave e organizadas em blocos que seguem a sequência: relacionadas ao acadêmico, relacionadas ao aluno e relacionadas ao contexto escolar.

QUADRO 2 - Palavras-chave e relatos relacionados aos aspectos positivos do Estágio

\begin{tabular}{|c|c|c|c|}
\hline $\begin{array}{c}\text { Palavras- } \\
\text { chave }\end{array}$ & Recortes 2015 & Recortes 2016 & Recortes 2017 \\
\hline $\begin{array}{c}\text { Contribuição } \\
\text { na formação } \\
\text { acadêmica }\end{array}$ & $\begin{array}{c}\text { [...] desafios que } \\
\text { contribuíram para a } \\
\text { nossa formação }\end{array}$ & $\begin{array}{c}{[\ldots . .] \text { Vivenciar tal prática }} \\
\text { traz segurança }[. . .] \\
\text { O dia a dia da sala de }\end{array}$ & $\begin{array}{c}{[\ldots . .] \text { nos dá a chance de }} \\
\text { trabalhar diretamente } \\
\text { com a realidade das }\end{array}$ \\
\hline
\end{tabular}




\begin{tabular}{|c|c|c|c|}
\hline $\begin{array}{l}\text { Frequência: } \\
2015-26 \\
2016-18 \\
2017-14\end{array}$ & $\begin{array}{c}\text { acadêmica. A tomada } \\
\text { de decisão e forma de } \\
\text { abordagem de alguns } \\
\text { conteúdos [...] } \\
\text { (Relatório 3) } \\
\text { [...] experiência } \\
\text { significativa para o } \\
\text { processo de formação } \\
\text { docente, constituindo- } \\
\text { se como um momento } \\
\text { rico e importante em } \\
\text { que pode evidenciar } \\
\text { no contexto fora de } \\
\text { sala de aula a relação } \\
\text { entre teoria e a prática. } \\
\text { [...] (Relatório 5) }\end{array}$ & $\begin{array}{c}\text { aula mostra um } \\
\text { aprendizado de suma } \\
\text { importância, a vivência, } \\
\text { o contato com os } \\
\text { alunos, ali o acadêmico } \\
\text { desiste de tal profissão } \\
\text { ou ratifica sua escolha } \\
\text { feita no passado [...] } \\
\text { (Relatório 5) } \\
\text { [...] O Estagio } \\
\text { Supervisionado I nos } \\
\text { mostrou a importância } \\
\text { de termos essa parte } \\
\text { prática durante nossa } \\
\text { formação acadêmica } \\
\text { [...] (Relatório 7) }\end{array}$ & $\begin{array}{l}\text { nossas escolas, e também } \\
\text { aplicar todos os } \\
\text { conhecimentos adquiridos } \\
\text { até o momento, isso é } \\
\text { muito importante para a } \\
\text { formação [...] (Relatório 9) } \\
\\
\text { [...] sair com a certeza de } \\
\text { que acrescentamos algo } \\
\text { à vida de cada um e eles } \\
\text { também agregaram } \\
\text { muito à nossa formação e } \\
\text { nos deixaram um } \\
\text { aprendizado para } \\
\text { levarmos adiante em } \\
\text { nossas vidas [...] (Relatório } \\
\text { 4) }\end{array}$ \\
\hline $\begin{array}{l}\text { Importância } \\
\text { da EF } \\
\text { Frequência: } \\
2015 \text { - } 07 \\
2016 \text { - } 02 \\
2017 \text { - } 03\end{array}$ & $\begin{array}{c}\text { [...] o maior legado } \\
\text { deixado pelo estágio I } \\
\text { é a constatação de } \\
\text { quão importante é a } \\
\text { figura do professor } \\
\text { nesta fase da vida [...] } \\
\text { (Relatório 8) } \\
\\
\text { [...] o mais significativo } \\
\text { foram as palavras da } \\
\text { professora [...] o que } \\
\text { demonstra que a EF na } \\
\text { El, de forma planejada, } \\
\text { sistematizada, com } \\
\text { embasamento é } \\
\text { necessária [...] } \\
\text { (Relatório 5) }\end{array}$ & $\begin{array}{c}\text { [...] nos proporcionou } \\
\text { uma experiência impar } \\
\text { ao observar quão } \\
\text { fundamental uma única } \\
\text { aula de educação física } \\
\text { escolar é para o } \\
\text { desenvolvimento das } \\
\text { crianças, uma vez que } \\
\text { ao termino de uma aula } \\
\text { eles eram capazes de } \\
\text { refletir e formar o } \\
\text { conhecimento sobre o } \\
\text { assunto [...] (Relatório 1) }\end{array}$ & $\begin{array}{c}\text { [...] não fossem vistas } \\
\text { como uma simples } \\
\text { brincadeira para } \\
\text { desgastar a energia das } \\
\text { crianças a intenção atrás } \\
\text { daquela ludicidade } \\
\text { existiam objetivos que } \\
\text { favoreciam o } \\
\text { desenvolvimento físico, } \\
\text { cognitivo e afetivo dos } \\
\text { alunos [...] (Relatório 2) } \\
\text { [...] fez refletir muito sobre } \\
\text { a importância que a nossa } \\
\text { área tem nessa faixa } \\
\text { etária, trabalhar com o } \\
\text { aluno o ápice da sua } \\
\text { formação motora e de } \\
\text { fácil aprendizagem é } \\
\text { essencial [...] (Relatório 10) }\end{array}$ \\
\hline $\begin{array}{c}\text { Participação } \\
\text { dos } \\
\text { estudantes } \\
\text { Frequência: } \\
2015 \text { - } 36 \\
2016 \text { - } 65 \\
2017 \text { - } 55\end{array}$ & $\begin{array}{c}\text { [...] Teve-se grande } \\
\text { aceitação e } \\
\text { participação, [...] para } \\
\text { muitos aquelas } \\
\text { atividades eram } \\
\text { novidades [...] } \\
\text { (Relatório 8) } \\
\\
\text { [...] conseguimos atingir } \\
\text { nosso objetivo, que foi } \\
\text { conquistar os alunos e } \\
\text { fazer com que todos } \\
\text { participassem [...] } \\
\text { (Relatório 1) }\end{array}$ & $\begin{array}{l}\text { [...] As atividades } \\
\text { propostas tiveram ótima } \\
\text { aceitação, e a turma } \\
\text { realizou todas as } \\
\text { atividades com êxito [...] } \\
\text { (Relatório 1) } \\
\text { [...] logo de início eles já } \\
\text { nos reconheceram } \\
\text { como professores } \\
\text { participaram e } \\
\text { adoraram as atividades } \\
\text { [...] (Relatório 3) }\end{array}$ & $\begin{array}{l}\text { [...] Minha percepção foi } \\
\text { que os alunos estavam } \\
\text { dispostos a participar da } \\
\text { aula, e a cada atividade } \\
\text { demonstraram interesse } \\
\text { em aprender mais. [...] } \\
\text { (Relatório 11) } \\
\text { [...] a turma se mostrou } \\
\text { muito participativa, } \\
\text { permitiram-se e } \\
\text { entregaram-se para as } \\
\text { atividades [...] (Relatório 5) }\end{array}$ \\
\hline $\begin{array}{l}\text { Evolução da } \\
\text { turma } \\
\text { Frequência: } \\
2015 \text { - } 03\end{array}$ & $\begin{array}{l}\text { [...] podemos perceber } \\
\text { a evolução de todos } \\
\text { da turma [...] Ver que } \\
\text { de alguma maneira } \\
\text { acrescentamos algo }\end{array}$ & $\begin{array}{l}\text { [...] Não há como não } \\
\text { perceber a melhora no } \\
\text { desenvolvimento social, } \\
\text { cognitivo e psíquico } \\
\text { desde o início até o final }\end{array}$ & $\begin{array}{c}\text { [...] Ao final das } \\
\text { intervenções é possível } \\
\text { constatar os ganhos dos } \\
\text { alunos em comparativo } \\
\text { ao inicio das intervenções, }\end{array}$ \\
\hline
\end{tabular}




\begin{tabular}{|c|c|c|c|}
\hline $\begin{array}{l}2016-07 \\
2017-20\end{array}$ & $\begin{array}{l}\text { para a vida dessas } \\
\text { crianças é muito } \\
\text { gratificante. [...] } \\
\text { (Relatório 7) }\end{array}$ & $\begin{array}{c}\text { [...] (Relatório 3) } \\
\text { [...] em um curto período } \\
\text { de tempo, obtivemos } \\
\text { grandes resultados de } \\
\text { melhoramento dos } \\
\text { padrões motores da } \\
\text { grande maioria dos } \\
\text { alunos [...] (Relatório 1) }\end{array}$ & $\begin{array}{c}\text { [...] (Relatório 6) } \\
\text { [...] É notável a evolução } \\
\text { de todos eles, não só em } \\
\text { questão de habilidades } \\
\text { físicas, mas também na } \\
\text { questão dos gêneros que } \\
\text { é muito forte na escola. } \\
\text { [...] (Relatório 8) }\end{array}$ \\
\hline $\begin{array}{c}\text { Melhora } \\
\text { comportame } \\
\text { ntal } \\
\text { Frequência: } \\
2015-03 \\
2016-03 \\
2017 \text { - } 05\end{array}$ & $\begin{array}{c}\text { [...] conseguimos } \\
\text { observar um avanço } \\
\text { significante quanto ao } \\
\text { comportamento desses } \\
\text { alunos [...] (Relatório 2) } \\
\text { [...] Pode-se observar } \\
\text { que aprenderam a } \\
\text { respeitar as regras e } \\
\text { ouvir os comandos } \\
\text { dados, [...] (Relatório 3) }\end{array}$ & $\begin{array}{c}\text { [...] percebo que o uso } \\
\text { do apito que } \\
\text { combinamos no início é } \\
\text { menos necessário, [...] } \\
\text { (Relatório 8) } \\
\text { [...] ver o progresso nas } \\
\text { questões afetivas entre } \\
\text { os sexos, [...] mas a } \\
\text { percepção de que a } \\
\text { conduta foi mudada é } \\
\text { visível. [...] (Relatório 3) }\end{array}$ & $\begin{array}{c}\text { [...] As broncas surtiram } \\
\text { efeito na hora, e os alunos } \\
\text { melhoraram o } \\
\text { comportamento. } \\
\text { (Relatório 4) } \\
\text { [...] vale ressaltar que a } \\
\text { turma melhorou } \\
\text { significativamente no seu } \\
\text { comportamento [...] } \\
\text { (Relatório 5) }\end{array}$ \\
\hline $\begin{array}{l}\text { Recepção } \\
\text { no ambiente } \\
\text { escolar } \\
\text { Frequência: } \\
2015 \text { - } 06 \\
2016-05 \\
2017 \text { - } 05\end{array}$ & $\begin{array}{l}\text { [...] Agradeço a escola } \\
\text { por nos disponibilizar o } \\
\text { espaço e se mostrar } \\
\text { sempre de portas } \\
\text { abertas ao nosso curso } \\
\text { dentro da educação } \\
\text { infantil, [...] (Relatório 7) } \\
\\
\text { [...] Quanto a nossa } \\
\text { recepção na escola, } \\
\text { foram todos muito } \\
\text { receptivos conosco. } \\
\text { [...] (Relatório 6) }\end{array}$ & $\begin{array}{c}\text { [...] Durante ambos } \\
\text { períodos (observações e } \\
\text { práticas), tivemos livre } \\
\text { acesso aos ambientes } \\
\text { da escola [...] em } \\
\text { nenhum momento } \\
\text { houve alguma restrição } \\
\text { [...] (Relatório 9) } \\
\text { [...] Outro ponto a ser } \\
\text { levantado foi à ótima } \\
\text { recepção por parte da } \\
\text { direção, coordenação e } \\
\text { professoras, além da } \\
\text { grande aceitação por } \\
\text { parte dos alunos [...] } \\
\text { (Relatório 1 }\end{array}$ & $\begin{array}{c}\text { [...] Fomos bem recebidos } \\
\text { pela escola, também pela } \\
\text { professora da turma e } \\
\text { auxiliar pedagógica, [...] } \\
\text { (Relatório 11) } \\
\text { [...] A receptividade da } \\
\text { equipe e o ambiente } \\
\text { acolhedor oportunizaram } \\
\text { a sedimentação de } \\
\text { conhecimentos, a } \\
\text { interação com as } \\
\text { professora da turma, bem } \\
\text { como o contato direto } \\
\text { com os alunos e os pais } \\
\text { fizeram com que a prática } \\
\text { fosse significativa. [...] } \\
\text { (Relatório 7) }\end{array}$ \\
\hline
\end{tabular}

Fonte: As autoras, 2017.

Durante a análise dos relatórios a Participação dos estudantes foi a palavra-chave com a maior frequência (156) desta categoria, e só no ano de 2016 contou-se 65 repetições em oito relatórios. Essa participação, talvez esteja relacionada as atividades lúdicas que prendem a atenção das crianças ou então, por ser em horário reduzido e fixo na rotina escolar. Para Souza e Silva (2013) os jogos e as atividades lúdicas são possibilidades que atraem o estudante e possuem um significado no ensino, proporcionando uma prática dinâmica e com o objetivo voltado para o desenvolvimento 
integral do educando. A partir dos recortes, também observou-se que a participação relaciona-se com a aproximação do professor e os estudantes, e interesse das crianças pelas atividades propostas.

A Contribuição na formação acadêmica foi à palavra-chave com segunda maior frequência identificada. Conforme as afirmações, os obstáculos enfrentados durante as intervenções fizeram com que os estagiários vivenciassem alguns aspectos da prática que talvez possam ser encontrados após a formatura e, também, colocar em prática a teoria que aprenderam nos semestres anteriores. Essa reflexão dos estagiários é aspecto importante para Pimenta e Lima (2005/2006), que justificam a necessidade de entrelaçar a teoria com a prática para desenvolver amplamente o processo de ensino, desconfigurando a ilusão de que os ECS são apenas as habilidades práticas necessárias para a docência. Essa separação apenas acarreta no empobrecimento da prática pedagógica desenvolvida. Conforme a citação é evidente a relevância das ações teórico-prático:

Nesse processo, o papel das teorias é o de iluminar e oferecer instrumentos e esquemas para análise e investigação, que permitam questionar as práticas institucionalizadas e as ações dos sujeitos e, ao mesmo tempo, se colocar elas próprias em questionamento, uma vez que as teorias são explicações sempre provisórias da realidade (PIMENTA e LIMA, 2005/2006, p.12).

Para Zabalza (2014) a contribuição do estágio não está associada somente a experiência acadêmica, envolve também as contribuições no desenvolvimento pessoal de cada estagiário, de como ele constrói os significados da experiência e como identifica a própria aprendizagem. Gardiner (1989, apud ZABALZA, 2014) afirmou que as contribuições das experiências do estágio devem ser reconhecidas no âmbito das aprendizagens do currículo formal e da aprendizagem do desenvolvimento pessoal.

O terceiro significado com maior frequência foi a Evolução da turma, percebeu-se, a partir das afirmações, que as intervenções do estágio proporcionaram às crianças um avanço no desenvolvimento motor, social e 
cognitivo. Associamos a essas afirmações a importância e a falta de um profissional de EF nessa etapa da Educação Básica.

Encontra-se nas escolas de El uma organização de horários destinados a prática de EF, porém, esse período é caracterizado como a hora do pátio/pracinha o que perde o foco de aulas planejadas, pois as crianças ficam soltas pelos espaços sem nenhuma orientação que objetive uma progressão no aprendizado, essa questão foi muito relacionada com a evolução do aprendizado das crianças durante as aulas dos estagiários. Comparando o "tempo livre" e a importância do movimento para o ensino infantil, descrita na legislação e identificada nos relatos, chega-se na importância que um profissional de EF tem no desenvolvimento e ampliação do aprendizado das crianças da primeira etapa da Educação Básica.

A importância se dá pela pluralidade de experiências adquiridas através das inúmeras manifestações da cultura corporal do movimento que são planejadas, proporcionando aos estudantes um aprimoramento crítico e social, o conhecimento da linguagem corporal, a emancipação para resolver desafios e o desenvolvimento das habilidades motoras básicas (BASEl, 2008). Aspectos que tornam relevante um período de formação mais amplo para que seja construído um conhecimento da cultura corporal do movimento adequado, o que enaltece a diferença de planejamento e as peculiaridades entre o Licenciado em EF e o professor Unidocente.

A partir das análises conseguimos fazer um "link" com o segundo significado apresentado no quadro 2, A importância da Educação Física, onde os estagiários afirmaram como pontos positivos a contribuição de aulas planejadas e estruturadas para o desenvolvimento integral das crianças.

A evolução que os estagiários identificaram talvez esteja associada as atividades estruturadas em objetivos específicos e organizadas conforme 0 contexto de cada turma que participou das vivências desses acadêmicos. Para Basei (2008) é importante trabalhar as especificidades do movimento desde a primeira infância, através de um planejamento que contemple as peculiaridades de cada etapa da El baseado no desenvolvimento cognitivo, social, afetivo e motor. 
Outro fato positivo mencionado nos relatórios é a Melhora comportamental, neste aspecto os estagiários relatam que durante o período de estágio conseguiram observar uma mudança no comportamento dos estudantes. Associando 0 comportamento frequentemente com a Agitação, percebe-se que o uso de estratégias e ajustes no planejamento fizeram com que os estudantes compreendessem os estagiários como professores, aumentando a afetividade e, por seguinte, melhorando o desenvolvimento das aulas. Em conformidade com esse pensamento, Amaral e Pereira (2013) salientam a necessidade dos educadores observarem esses aspectos visando sempre ações que contribuam para a mudança do comportamento. As autoras também mencionam a importância do aperfeiçoamento dos conhecimentos teóricos. A partir disto, consegue-se fazer um "link" com a contribuição das observações dos Supervisores de Estágio.

A Recepção ao ambiente escolar foi considerada como aspecto positivo, as afirmações mostram a importância dessa recepção para o bom andamento das intervenções, demonstrando que o auxílio da comunidade escolar influência no desenvolvimento das práticas e faz com que os estagiários sintam-se mais calmos e pertencentes àquela comunidade escolar. Esse aspecto positivo pode estar associado às percepções que a comunidade escolar tem em relação às contribuições que o componente curricular proporciona a elas. Zabalza (2014) relata os resultados de sua pesquisa, onde elenca as contribuições descritas pelos beneficiados nos estágios.

Ressalta-se ainda, um aspecto com frequência inferior a dez, mas que pode ser considerada importante, a Autonomia. As afirmações demonstram que a boa recepção pela escola deu autonomia para os acadêmicos escolherem e montarem seus planejamentos de ensino de acordo com as características de cada turma e cada ambiente físico. Conforme o exemplo do recorte a seguir,

[...] A aula no ar livre foi prazerosa, acredito que para nós e para os alunos. Conseguimos realizar as atividades proposta e senti mais 
liberdade para deixar que as brincadeiras seguissem sem ter que ficar controlando os participantes [...] (Relatório 3)

Ainda que associada a um aspecto positivo, a autonomia relatada pelos estagiários demonstrou, também, a dificuldade em desenvolver as aulas nos pequenos espaços adequados que a maioria das escolas possuía, tendo que priorizar atividades que não atrapalhassem as aulas ao redor.

\section{As dificuldades encontradas pelos estagiários nas intervenções dos ECS}

Os aspectos positivos apresentados no item 2 dos resultados, foram destacados como um acontecimento esperado ou não, que contribuiu na formação profissional de cada estagiário. Já as dificuldades foram norteadas como aspectos negativos que não corresponderam aos resultados esperados. Na análise desta categoria foram identificadas nove palavras-chave que foram classificadas como dificuldades enfrentadas durante as intervenções e algumas são apresentadas no quadro 3. A discussão das palavras-chave são agrupadas na mesma sequência anterior, relacionado aos acadêmicos, alunos e contexto escolar.

QUADRO 3 - Palavras-chave e recortes relacionadas as dificuldades

\begin{tabular}{|c|c|c|c|}
\hline $\begin{array}{l}\text { Palavras- } \\
\text { chave }\end{array}$ & Recortes 2015 & Recortes 2016 & Recortes 2017 \\
\hline $\begin{array}{c}\text { Controle } \\
\text { da turma } \\
\text { Frequência: } \\
2015 \text { - } 15 \\
2016 \text { - } 09 \\
2017 \text { - } 13\end{array}$ & $\begin{array}{l}\text { [...] Na El, certamente } \\
\text { mais do que nas outras } \\
\text { fases, a tarefa de } \\
\text { conduzir as aulas de } \\
\text { educação física não é } \\
\text { fácil (Relatório 8) } \\
\text { [...] foi difícil de } \\
\text { organiza-los para } \\
\text { realizar as atividades } \\
\text { [...] (Relatório 4) }\end{array}$ & $\begin{array}{c}\text { [...] O maior problema } \\
\text { neste inicio de aula foi o } \\
\text { controle sobre certos } \\
\text { alunos [...] (Relatório 2) } \\
\text { [...] A aula foi péssima, } \\
\text { eu estava nervoso e } \\
\text { ansioso, acredito que } \\
\text { minha colega também, } \\
\text { não conseguimos } \\
\text { controlar a turma [...] } \\
\text { (Relatório 4) }\end{array}$ & $\begin{array}{c}\text { [...] pude perceber que } \\
\text { haveria certa dificuldade } \\
\text { em controlar a turma, } \\
\text { muitos empurrões e } \\
\text { agitação [...] (Relatório 3) } \\
\text { [...] pelo local que era } \\
\text { maior ficou mais difícil de } \\
\text { controlar os alunos, pois o } \\
\text { espaço era muito grande } \\
\text { [...] (Relatório 10) }\end{array}$ \\
\hline $\begin{array}{l}\text { Inexperiênc } \\
\text { ia } \\
\text { Frequência: } \\
2015 \text { - } 00 \\
2016 \text { - } 07 \\
2017 \text { - } 06\end{array}$ & & $\begin{array}{c}\text { [...] foi bem complicada } \\
\text { ao meu ver, pois não } \\
\text { tínhamos experiência } \\
\text { com crianças dessa faixa } \\
\text { etária [...] (Relatório 6) } \\
\text { [...] a falta de } \\
\text { experiência [...]foi um } \\
\text { grande desafio, junto }\end{array}$ & $\begin{array}{c}\text { [...]nosso primeiro contato } \\
\text { com uma turma de ensino } \\
\text { infantil, tivemos algumas } \\
\text { dificuldades para aplicar } \\
\text { determinados exercícios e } \\
\text { resolver alguns conflitos } \\
\text { [...] (Relatório 8) } \\
\text { Apesar de termos poucos }\end{array}$ \\
\hline
\end{tabular}




\begin{tabular}{|c|c|c|}
\hline & $\begin{array}{c}\text { com toda a tensão em } \\
\text { montar planos com } \\
\text { atividades que fossem } \\
\text { de agrado dos alunos } \\
\text { [...] (Relatório 4) }\end{array}$ & $\begin{array}{l}\text { alunos nossa aulas foram } \\
\text { difíceis porque não temos } \\
\text { conhecimentos suficientes } \\
\text { com crianças [...] } \\
\text { (Relatório 1) }\end{array}$ \\
\hline $\begin{array}{l}\text { Dificuldade } \\
\text { s dos alunos } \\
\text { Frequência: } \\
2015 \text { - } 00 \\
2016 \text { - } 09 \\
2017 \text { - } 20\end{array}$ & $\begin{array}{c}\text { [...] a dificuldade motora } \\
\text { de alguns alunos em } \\
\text { realizar o que era } \\
\text { proposto [...] (Relatório 8) } \\
\text { [...] eles não sabiam o } \\
\text { que fazer, [...] tendo que } \\
\text { haver auxilio dos } \\
\text { professores [...] (Relatório } \\
\text { 3) }\end{array}$ & $\begin{array}{c}\text { [...] pudemos perceber } \\
\text { que as crianças tem } \\
\text { muitas dificuldades em } \\
\text { realizar a tarefa [...] } \\
\text { (Relatório 1) } \\
\text { [...] essas crianças } \\
\text { apresentam } \\
\text { características não } \\
\text { desenvolvidas em vários } \\
\text { aspectos [...] (Relatório 2) }\end{array}$ \\
\hline
\end{tabular}

Fonte: As autoras, 2017.

O controle da turma está associado ao comportamento das crianças e como os professores se posicionam com relação a este comportamento. Para Colucci e Novak (2013) o professor deve criar estratégias mais atraentes para diminuir a dispersão dos estudantes e conseguir desenvolver suas aulas, entre essas estratégias estão a formação continuada e adequação da prática pedagógica.

A insegurança e a falta de estudo por parte dos estagiários pode ser um aspecto que contribuí para essa dificuldade relatada. $O$ estagiário que consegue compreender a dinâmica do estágio, tem definidos seus objetivos e fundamentos, e entende as possibilidades curriculares consegue superar as dificuldades encontradas e desenvolve uma aula produtiva (PIMENTA e LIMA, 2012).

A inexperiência relatada pelos estagiários está relacionada ao pouco ou nenhum contato prévio com crianças da faixa etária e também a falta de vivências como professores. A partir das afirmações ficou evidente que por mais que os acadêmicos tenham componentes curriculares que trabalhem o ensino para $\mathrm{El}$, os mesmos não se sentem teoricamente preparados para conduzir uma turma dessa faixa de idade. Talvez essa dificuldade apresente uma lacuna na grade curricular desse curso, necessitando uma reestruturação nas vivências teórico-práticas no ensino da licenciatura. 
O estágio perdeu a característica de ser só um componente prático, é importante ter nos ECS o equilíbrio entre a teoria e a prática e o envolvimento de todas as disciplinas dos cursos de graduação. Pimenta e Lima (2012) explicam a trajetória histórica dos estágios e a presença da prática dentro do componente curricular, entretanto, enfatizam a necessidade da reorganização curricular a partir das modificações da educação. Para elas, é importante que haja uma reflexão das práticas pedagógicas, possibilitando a relação dos saberes teóricos e práticos desde o início da graduação, fazendo com que os estudantes enriqueçam a sua escolha pela docência a partir da identificação da realidade que os ECS proporcionam.

Para as autoras, o ECS é um intercâmbio, durante a formação, entre a Universidade e o campo de estágio, e ambos necessitam do processo teórico-prático para que ocorra a reflexão e a análise das ações, tanto dos professores como dos estagiários, e dos diferentes espaços da escola, a fim de justificar as transformações necessárias da docência.

Ao identificar as palavras-chave relacionadas aos alunos, o aspecto com a maior frequência foi a Dificuldade dos alunos, o que está relacionado ao precário desenvolvimento motor e cognitivo das crianças. Pode-se associar essa análise aos níveis de aprendizagem de cada educando e também a deficiência do ensino. A percepção sobre o ensino precário do movimento corporal na El vai de encontro com o que Leite et al. (2016) afirma sobre a contextualização do brincar, onde salienta que atividades sistematizadas contribuem mais no desenvolvimento dos estudantes do que o brincar por brincar.

Os demais significados identificados referentes aos alunos e que tiveram frequência de apuramento inferior a dez são: Indisciplina (6), Não participação de alguns alunos (09) e Alunos de inclusão (03).

Ao analisar o recorte [...] as professoras responsáveis das turmas não impunham limites nos alunos, principalmente na etapa $V$, onde havia alunos que batiam na professora [...] (Relatório 2) percebe-se que a indisciplina interferiu de forma negativa e contribuiu para a dificuldade de controlar a 
turma (palavra-chave mais relatada pelos estagiários dentro das dificuldades). É alarmante os altos níveis de indisciplina no ambiente escolar, e com relação a este aspecto não se pode culpabilizar apenas o professor.

Esse tema, também, está associado a importância da influência familiar no comportamento dos estudantes, como afirmam Ostetti e Brandão (2013). Os autores enfatizam a responsabilidade da família perante as noções de comportamento, regras, convívio, entre outros. Percebe-se na citação "[...] crianças sem limites em casa são sem limites na escola, desencadeando uma série de problemas [...] (OSTETTI e BRANDÃO, 2013, p.825)" a grande influência da família nessa dificuldade relatada pelos estagiários. Conforme Santos e Chilante (2013) a renúncia dos educadores (pais e professores) em ditar normas, resulta em indivíduos egocêntricos e despreparados para o convívio social. Para Colucci e Novak (2013) a indisciplina também está relacionada a estratégias dos estudantes para chamar atenção e tentar se sobressair aos demais.

As dificuldades relatadas com os alunos de inclusão foram associadas a inexperiência, o grau das limitações diagnosticadas e a falta do conhecimento teórico necessário para desenvolver uma aula que integrasse toda a turma, identificado no recorte "[...] dificuldade foi organizar a turma, pois tendo duas crianças especiais se tornava difícil ministrar as aulas [...] (Relatório 1)". Visto que o currículo do curso só dispõe a disciplina de Educação Física Adaptada no último semestre da licenciatura, essa organização curricular talvez tenha colaborado para essa percepção dos acadêmicos.

Em uma pesquisa com estagiários de EF realizada por Krug et al. (2017) com o objetivo de analisar as dificuldades com alunos de inclusão, os autores identificaram essas mesmas percepções relatadas, entre outras. Essas dificuldades estavam mais relacionadas aos aspectos pedagógicos do que os estruturais, confirmando a complexidade e variedade de influências que permeiam o ambiente escolar, extrapolando as causas das dificuldades encontradas na docência. 
A relação das dificuldades com o contexto escolar foi identificada nos seguintes recortes:

[...] a presença da professora deles atrapalhou um pouco. [...] (Relatório 8);

[...] O que nos deixou um tanto chateados foi o desrespeito de algumas professoras de outras turmas, perante o material utilizado por nós, na qual seus alunos danificaram e elas nada fizeram para corrigir ou não deixar que isso acontecesse, [...] (Relatório 3);

[...] a falta de conhecimento dos alunos dos locais utilizados para as práticas, [...] (Relatório 8);

Dentro desta relação identificou-se quatro palavras-chave (Presença da titular (06), Conflitos com a escola (04), Desconhecimento dos espaços da escola (03) e a Não importância da Educação Física (01)) que não foram apresentadas no quadro por apresentarem frequência de apuramento inferior a dez.

A presença ou não presença da professora titular da turma foi classificada como um aspecto negativo para os estagiários. A presença, em alguns momentos, fez com que as crianças descentralizassem o estagiário como professor responsável durante aquele período. E a não presença da titular foi relacionada ao controle da turma, para os estagiários se a professora acompanhasse as aulas poderia ajudar no controle da indisciplina dos educandos, visto que são os professores que conhecem melhor as atitudes de cada criança. Essa palavra-chave pode ser associada a discussão da troca de experiência que o estágio proporciona aos acadêmicos e professores.

Para Farias et al (2007) a criança necessita de um aprendizado amplo e para que consigam assimilar melhor o conhecimento seria necessário um trabalho coletivo, uma troca de experiências entre os professores de sala e os estagiários de EF, uma construção interdisciplinar. Conforme o que foi analisado, os acadêmicos que conseguiram ter uma ligação com as professoras titulares relataram aspectos positivos que contribuíram para um bom andamento das práticas.

Os conflitos com a escola foram associados à falta de respeito de outros professores com a organização dos materiais dos estagiários e alguns contratempos nas normas da escola para realização dos estágios. Neste 
aspecto salienta-se a não compreensão das contribuições dos Estágios para a comunidade escolar, e talvez uma disputa por espaço de trabalho e "status". E ainda, é possível associar a não importância da EF, apontada para algumas escolas nesta discussão.

Nesse sentido, cabe ressaltar que algumas Unidocentes ainda internalizam a cultura do notório saber, elas sabem da importância do movimento para essa faixa etária, mas defendem a ideia de que são capazes de desenvolver o ensino. Entretanto, não levam em consideração a necessidade da sistematização, do planejamento e do tempo de formação dos professores especialistas. Talvez essa não valorização do profissional de EF pelas demais professoras está, também, associado a questões financeiras, visto que com o ingresso do Professor de EF na El as professoras Unidocentes perderiam o acréscimo no salário para desenvolver tal função.

Corroborando com este pensamento, Sayão (1999) identificou em um dos seus estudos a disputa por espaços e "status" entre as professoras de sala e os professores especialistas. Para a autora a disputa das áreas se dá pelo tempo, remuneração, espaço pedagógico, especificidade do conhecimento e também pelo status, onde o profissional de EF precisa do curso superior e as Unidocentes, em sua maioria, possuem o curso técnico.

Ainda com relação às dificuldades ou intervenções negativas apontadas pelos estagiários, é possível destacar a Interferência climática (2015 - 09; 2017 - 07) como uma das palavras-chave que apresentaram a frequência total superior a dez, mas por não ter relação com os acadêmicos, os alunos e o contexto escolar, percebeu-se como mais coerente sua discussão apenas ao longo do texto. As dificuldades relatadas foram em relação aos dias de chuva e frio, que resultaram na infrequência dos alunos e na falta de espaços adequados para as aulas.

[...] Dia de chuva e os espaços que a escola disponibiliza estavam um pouco ruins de trabalhar [...] (Relatório 3)

[...] fomos pegos de surpresa pelo mau tempo e com isso nosso planejamento em desenvolver atividades externas teve que ser revisto [...] (Relatório 7)

[...] ponto negativo que tive foi a dificuldade em realizar as aulas pelas questões climáticas [...] (Relatório 10) 
Esse aspecto foge do controle dos estagiários, pois é um fator ambiental e torna-se impossível dos acadêmicos preverem ou modificarem. Conforme Copetti et al (2010), essa barreira relatada pelos estagiários evidencia uma característica ambiental da região geográfica Sul do Brasil, onde a instabilidade climática dessa região é fator determinante para as adversidades da prática de atividade física. Esse fator, talvez seja relatado em todos os anos dos Estágios na El, visto que eles são sempre realizados no primeiro semestre do ano junto com o início do outono e inverno.

\section{A relação e conflitos com os professores titulares e os supervisores do ECS}

Com o intuito de melhor apresentar esta categoria os recortes foram organizados com base em duas palavras-chave principais: Auxílio dos professores titulares e Presença dos supervisores.

O Auxílio dos professores caracteriza-se como uma contribuição no desenvolvimento das intervenções, esse companheirismo entre estagiário e professor titular da turma transmite aos educandos uma confiança e reconhecimento aos estagiários.

[...] O apoio das professoras teve fundamental importância no nosso aprendizado, porque ao mesmo tempo em que nos davam autonomia para resolver problemas e tomar decisões, se disponibilizavam para auxiliar nas dificuldades. [...] (Relatório 7)

[...] As professoras foram parte principal nas nossas aulas com suas contribuições, sempre prontas a nos ajudar e a coordenador também. [...] (Relatório 4)

[...] a professora da turma e a assistente foram super compreensivas e me ajudaram bastante neste processo. [...] (Relatório 10)

Com base nos recortes, percebe-se que o acompanhamento do professor titular contribui na formação dos acadêmicos, visto que ainda estão no processo de aprendizagem e em determinadas situações não saibam como intervir, sendo importante essa troca de experiência a partir da visão de um professor que já vivenciou certos obstáculos e, também, por conhecer melhor a turma. Indo ao encontro da afirmação de Sayão:

A participação das professoras regentes e das auxiliares é indispensável nos momentos em que o professor de Educação Física está coordenando uma atividade, assim como o inverso disto. Isto possibilita os/as profissionais conhecerem melhor as crianças e 
construírem vínculos entre os adultos que qualificam o trabalho pedagógico (SAYÃO, 2004, p.30).

A Presença dos supervisores, na visão dos acadêmicos associa-se a aspectos negativos e positivos. A partir das análises dos relatórios observa-se que a contribuição ou não dos professores supervisores pode influenciar na formação dos acadêmicos. Como ressaltam Pimenta e Lima (2005) a orientação para formação à docência é uma troca de experiências que se dá pela aproximação da realidade pelo complemento teórico, analisar e criticar as possíveis soluções de enfrentamentos encontrados por todos os estagiários é papel dos professores orientadores.

Nesse sentido, identifica-se na afirmação [...] infelizmente a professora orientadora não estava presente nessa, a aula foi muito boa graças aos conselhos que ela deu [...] (Relatório 2) a contribuição das observações dos supervisores durante o desenvolvimento das aulas, um olhar com mais experiência e de fora do contexto percebe os pequenos detalhes que os estagiários durante suas práticas não conseguem identificar.

É notável nos relatos a importância da presença dos supervisores nas vivências práticas, mesmo que a expectativa da presença de alguém que não faz parte da rotina possa vir a atrapalhar o controle da turma, visto que o nervosismo acaba bloqueando as atitudes dos estagiários. Identificou-se esse receio e insatisfação nas seguintes afirmações:

[...] A expectativa que gera quando chegamos para dar nossa aula é bastante incômoda, vamos ou não vamos ser observados hoje? Ficamos ansiosos pela visita porque precisamos saber como estamos, uma opinião que nos oriente para a preparação da próxima aula. [...] (Relatório 4);

[...] uma maior frequência nas observações das aulas por parte dos professores orientadores trariam maiores orientações a este acadêmico que a partir delas teria um melhor direcionamento a ser seguido. [...] (Relatório 5)

[...] Aula desenvolvida com bastante dificuldade por não saber como lidar o enfrentamento de receber visita dos professores orientadores fez com que tivesse um pouco de nervosismo para desenvolver as atividades propostas. [...] (Relatório 6).

A expectativa da observação gera um desconforto nos acadêmicos, pois ficam preocupados se estão desenvolvendo bem as práticas e alguns 
tem medo de que os orientadores deem uma nota muito baixa. Alguns estagiários ainda não compreenderam que as visitas dos professores orientadores servem para contribuir e auxiliar no desenvolvimento das aulas e não para atrapalhar. Evidenciando que ainda é necessário que os estudantes conceituem as supervisões de estágios como interações entre os envolvidos, extinguindo o significado de superioridade que o termo supervisão denota. Pimenta e Lima justificam sucintamente a importância da relação dos professores escolares, estagiários e supervisores na seguinte citação:

As atividades de supervisão que acontecem no estágio requerem aproximação e distanciamento, partilha de saberes, capacidade de complementação, avaliação, aconselhamento, implementações de hipóteses de solução para os problemas que, coletivamente, são enfrentados pelos estagiários (PIMENTA E LIMA, 2012, p.114).

A não presença dos Orientadores ou o número reduzido de visitas resultou em relatos de percepções negativas, muitos afirmaram que se tivessem recebido mais observações teriam tido mais aspectos positivos durante as vivências, a partir dos relatos, a experiência dos supervisores contribuiria para as dificuldades encontradas na prática.

Segundo Zotovici et al (2013), os anos de vivências com estágios dos professores universitários caracterizam as contribuições como imprescindíveis para a formação dos discentes, pois a bagagem de experiências, em contexto diferentes, acabam enriquecendo os comparativos das práticas pedagógicas e, consequentemente, auxiliando de forma crítica as necessidades dos futuros docentes.

Os referidos autores também comentam uma realidade encontrada no universo deste estudo, que é a não exclusividade do docente universitário para os estágios. Além dos estágios o professor orientador, também, encontra-se envolvido com outras disciplinas; orientações de TCC, atividades de Pós-graduação e grupos de estudos e pesquisas; o qual não consegue suprir sozinho todas as necessidades da carga horária que as observações e demais burocracias do ECS exigem, acompanhando na maioria das vezes à distância. 
Esta problemática nos alerta para a necessidade de mais docentes envolvidos nesse processo, visto que é primordial para a formação inicial dos discentes, e também para que os estagiários busquem mais orientações, seja durante as aulas teóricas do componente ou em encontros marcados fora do horário de estágio ou aula, e não somente fiquem na espera das observações para acalentar seus anseios.

Para Zotovici et al (2013), a relação entre professor e estagiário nem sempre é de caráter harmônico, porém, torna-se necessário uma cumplicidade que garanta as contribuições na formação, proporcionando o desenvolvimento de todos os envolvidos. Para os autores, o envolvimento dos professores da escola e da Universidade aprimorariam as experiências dos estagiários e a participação dos professores colaborariam com as dificuldades enfrentadas na prática, amenizando a ausência dos supervisores. Para complementar a importância da relação das três esferas envolvidas nos ECS, Sayão (1999) reafirma a necessidade do trabalho coletivo, ultrapassando as individualidades específicas de cada área, possibilitando, a troca a partir do diálogo e integração entre os profissionais da El.

\section{PALAVRAS CONCLUSIVAS}

Ao retomarmos o objetivo desta pesquisa que foi analisar as percepções referentes às experiências positivas e negativas que os estagiários de EF encontraram no desenvolvimento do ECS na El, destaca-se a partir das categorias de análise que foram identificadas 25 palavras-chave que nortearam as discussões desse trabalho. Conforme a frequência apurada em cada palavra-chave as que tiveram, durante os três anos, analisados a maior frequência foram: em relação aos aspectos negativos Agitados (73); em relação aos aspectos positivos - Participação (156); e quanto as dificuldades - Controle da turma (37).

A semelhança das turmas de estágios $(2015,2016$ e 2017) está nessas três palavras-chave, mesmo sendo de categorias diferentes acabam associando-se. A dificuldade em controlar a turma na maioria das 
afirmações foi associada ao comportamento das crianças, e nesse caso, a agitação é um dos fatores determinantes para a não realização ou reorganização das aulas dos estagiários. O descontrole da turma geralmente acontece pela indisciplina dos educandos ou pela insegurança do estagiário. Já a agitação, pode ser associada a falta de estímulos prazerosos para os estudantes, longo período de desenvolvimento da atividade, e também, atividades não adequadas para a faixa de idade das crianças.

Identificou-se que os relatos das dificuldades do estágio e comportamento das crianças incorporaram características negativas para o desenvolvimento das intervenções na El. Porém, mesmo com esses aspectos, a frequência de apuramento da palavra-chave "participação dos estudantes nas aulas dos estagiários" (156), mencionada nos relatórios indicou que os fatos negativos não foram determinantes para o insucesso das intervenções práticas. Pelo contrário, as dificuldades analisadas nos relatórios fizeram os acadêmicos buscarem novos meios de ações que explorassem a pluralidade de habilidades de forma atrativa, dinâmica, específica e objetiva dos diferentes indivíduos envolvidos nessa vivência.

A relação dessas palavras-chave permite concluir que as experiências dos estágios se classificam em negativas e positivas, entretanto, ambos aspectos denotam contribuições para a formação acadêmica e pessoal de cada estagiário. Além da formação para o mercado de trabalho, o estagiário desenvolve o senso crítico para diferentes conflitos (falta de estrutura física, familiar ou escolar) e experiências que o façam repensar a sua prática.

Por fim, identifica-se com os achados, que a interação entre Universidade e Escola abrange muito mais do que a contribuição na formação acadêmica dos discentes, os benefícios das intervenções vão além do cumprimento da carga horária e se ramificam aos novos conhecimentos e desenvolvimento cognitivo, social, motor e cultural de todos os participantes das experiências dos estágios.

Nesse sentido, ao finalizar este estudo avalia-se que os aspectos encontrados não se diferem muito de outras pesquisas e contextos e, que as 
percepções sofrem com fatores de indisciplina, falta de respeito e impaciência semelhantes aos demais problemas da sociedade. Com isto, buscou-se demonstrar a comunidade acadêmica envolvida nesse estudo as múltiplas contribuições que o componente Estágio Curricular Supervisionado proporciona e também, evidenciar a importância da criação de estudos a partir da diversidade de material teórico que a comunidade Universitária desenvolve em cada ano de graduação.

\section{REFERÊNCIAS}

AMARAL, L. O.; PEREIRA, C. D. O bullyng no âmbito escolar público estadual. Jornada de Pedagogia da FAFIPA (11: 2013: Paranavaí, Pr). Anais.../ XII Jornada de Pedagogia. - Paranavaí, Pr: Faculdade Estadual de Educação, Ciências e Letras de Paranavaí. Departamento de Educação, 2013.

BARDIN, L. Análise de conteúdo. São Paulo: Edições 70, 2011.

BASEl, A. P. A Educação Física na educação Infantil: a importância do movimentar-se e suas contribuições no desenvolvimento da criança. Revista Iberoamericana de Educación, n. ${ }^{\circ}$ 47/3 - 25 de outubro de 2008.

BRASIL. Lei de Diretrizes e Base da Educação Nacional. Lei número 9394, art 29 de 20 de dezembro de 1996.

CANDREVA, T.; CASSIANE, V.; RUY, M. P.; THOMAZINI, L.; CESTARI, H. F.; PRODÓCIMO, E. A agressividade na Educação Infantil: o jogo como forma de intervenção. Revista Pensar a prática, v.12, n.1, 2009.

COLUCCI, A. S.; NOVAK, M. S. J. Indisciplina escolar: alguns apontamentos. Jornada de Pedagogia da FAFIPA (11.: 2013: Paranavaí, Pr). Anais.../ XII Jornada de Pedagogia. - Paranavaí, Pr: Faculdade Estadual de Educação, Ciências e Letras de Paranavaí. Departamento de Educação, 2013.

COPETTI, J.; NEUTZLING, M. B.; SILVA, M. C. Barreiras à prática de atividades físicas em adolescentes de uma cidade do sul do Brasil. Revista Brasileira de Atividade Física e Saúde, v.15, n.2, 2010.

FARIAS, D. C.; GOULART, M. C.; AMORIM, S. H. Os principais problemas da Educação Física e suas relações com a realidade na/da Educação Infantil. Revista Motrivivência, Ano 19, № 29, P.87-102, Dezembro, 2007.

FAZENDA, I. C. A.; PICONEZ, S. C. B. A prática de ensino e o estágio. Campinas/SP: Papirus, 1991. (Coleção Magistério: Formação e trabalho Pedagógico)

GODOY, A. S. Pesquisa qualitativa: Tipos fundamentais. Revista de Administração de Empresas / EAESP / FGV, São Paulo, Brasil, 1995.

GONSALVES, E. P. Conversas sobre iniciação à pesquisa científica. Campinas, SP: Editora Alínea, 2001.80p 
GONÇALVES, J. P. A falta de limites em crianças da Educação Infantil segundo a perspectiva das professoras. Congresso Nacional de Educação (7:2007 nov. 5-8: Curitiba, PR) Anais do VII Congresso Nacional de Educação - EDUCERE [recurso eletrônico]: saberes docentes: edição internacional; Curitiba, $2007 . \quad$ Disponível em: <http://www.pucpr.br/eventos/educere/educere2007/anaisEvento/arquivos/ Cl-422-04.pdf>. Acesso em: 01 de outubro de 2017.

KRUG, H. N.; CONCEIÇÃO, V. J.S.; KRUG, R. R.; FLORES, P. P.; KRUG, M. R. AS dificuldades enfrentadas pelos acadêmicos de Educação Física em situação de estágio curricular supervisionado frente aos alunos com deficiência. Revista Eletrônica Itinerarius Reflectionis, UFG/REJ, v,13, n.1:2017.

KRUG, H. N.; KRUG, R. R.; MARQUES, M. N.; CONCEIÇÃO, V. J. S. Ser professor na escola: de aluno a professor no estágio curricular supervisionado na licenciatura em Educação Física. Revista Linhas, Florianópolis, v. 16, n. 30, p. 248 - 269, jan./abr. 2015.

KRUG, R. R.; KRUG, H. N. Os estágios curriculares supervisionados na licenciatura do CEFD/UFSM: a confirmação ou não do ser professor de educação física... na escola. Revista Formação@Docente - Belo Horizonte vol. 5, no 2, jul/dez 2013.

KULCSAR, R. O estágio supervisionado como atividade integradora. In: FAZENDA, I. C. A.; PICONEZ, S. C. B. (Org.). A prática de ensino e o estágio supervisionado. Campinas/SP, 1991. p. 63. (Coleção Magistério: Formação e trabalho pedagógico)

LEITE, J. O.; CAUPER, D. A. C.; MARTINS, P. C. Saberes e Movimento - O diálogo entre Educação Física e Educação Infantil: Reflexões a partir da prática pedagógica. Cadernos de Formação RBCE, p. 9-19, mar. 2016

MELLO, A. S.; SANTOS, W. S.; KLIPPEL, M. V.; ROSA, A. P.; VOTRE, S. J. Educação Física na Educação Infantil: Produção de saberes no cotidiano escolar. Revista Brasileira de Ciência e Esporte, Florianópolis, v. 36, n. 2, p. 467-484, abril/junho 2014.

MENTZ, P. Educação Física nos anos iniciais do Ensino Fundamental: narrativas de estagiárias do curso de Pedagogia. Trabalho Conclusão de Curso, UFRGS. Porto Alegre, $2011.38 \mathrm{f}$

MIRANDA, S.; AFONSO, C. A. A Educação Física na escola e o desenvolvimento motor. EDUCERE - Congresso de Educação do PUCPR. (6.:2006:Curitiba) 6.Congresso de Educação da PUCPR. - Curitiba, 2006. Disponível em: <http://www.pucpr.br/eventos/educere/educere2006/anaisEvento/docs/Cl085-TC.pdf>. Acesso em: 01 de outubro de 2017.

NÓVOA, A. Desafios do trabalho do professor no mundo contemporâneo. Sindicato dos professores, São Paulo. 2007. 
OLIVEIRA, M. E.; FERNANDES, S. F.; FARIA, L. C.F. A musicalização, o lúdico e a afetividade na Educação Infantil. Colloquium Humanarum, vol.10, $\mathrm{n}$. Especial, Jul-Dez, 2013, p. 1411-1418.

OSTETTI, S. C.; BRANDÃO, E. C. O Bullyng no âmbito escolar e duas consequências no aprendizado. Jornada de Pedagogia da FAFIPA 111 .: 2013: Paranavaí, Pr). Anais.../ XII Jornada de Pedagogia. - Paranavaí, Pr: Faculdade Estadual de Educação, Ciências e Letras de Paranavaí. Departamento de Educação, 2013.

PIMENTA, S. G. O estágio na formação de professores: unidade entre teoria e prática?. Caderno de Pesquisa, São Paulo, n.94, p.58-73, Agosto, 1995.

PIMENTA, S. G.; LIMA, M. S. L. Estágio e docência: diferentes concepções. Revista Poíesis, v.3, n. 3 e 4, p.5-24, 2005/2006.

PIMENTA, S. G.; LIMA, M. S. L. Estágio e docência. 7. Ed, São Paulo: Editora Cortez, p.296, 2012.

RODRIGUES, A. A.; MOLINA, A. A. Relações históricas entre literatura infantil e Educação Infantil: Breves considerações. In: XII Jornada de Pedagogia da FAFIPA (11.: 2013: Paranavaí, Pr). Anais.../ XII Jornada de Pedagogia. Paranavaí, Pr: Faculdade Estadual de Educação, Ciências e Letras de Paranavaí. Departamento de Educação, 2013.

SAYÃO, D. T. Educação Física na educação infantil: riscos, conflitos e controvérsias. Revista Motrivivência, Florianópolis, SC. Ano Xl, $N^{0} 13$, Novembro/1999.

SAYÃO, D. T. O Fazer Pedagógico do/a Professor/a de Educação Física na Educação Infantil. Caderno da Formação em Serviço da Rede Municipal de Ensino de Florianópolis, P.M.F. P.29, 2004

SILVA, S. A. P. S. Desenvolvimento do pensamento crítico-criativo e os estágios curriculares na área de Educação Física. Revista Brasileira de Ciência e Movimento, 2003; 11 (3): 37-44

SOUZA, F. O. A.; SILVA, R. T. M. O papel do lúdico no processo de ensino e aprendizagem. Jornada de Pedagogia da FAFIPA (1 1.: 2013: Paranavaí, Pr). Anais.../ XII Jornada de Pedagogia. - Paranavaí, Pr: Faculdade Estadual de Educação, Ciências e Letras de Paranavaí. Departamento de Educação, 2013.

ZABALZA, M. A. O estágio e as práticas em contextos profissionais na formação universitária. 1 ${ }^{a}$ Edição, São Paulo: Editora Cortez, p.327, 2014.

ZOTOVICI, S. A.; MELO, J. B.; CAMPOS, M. Z.; LARA, L. M. Reflexões sobre o estágio supervisionado no curso de licenciatura em Educação Física: Entre a teoria e a prática. Revista Pensar a Prática, Goiânia, v. 1 6, n. 2, p. 320618 , abr./jun. 2013.

Recebido em: Novembro de 2017

Aprovado em: Março de 2018 